Universidade Tecnológica Federal do Paraná - UTFPR

Campus Ponta Grossa - Paraná - Brasil

ISSN: 1981-3686 / v. 02, n. 01: p. 87-94, 2008
Revista Brasileira deTecnologia

Agroindustrial

\title{
ELABORACÃO DE UMA BARRA DE CEREAIS COMO ALIMENTO COMPENSADOR PARA PRATICANTES DE ATIVIDADE FÍSICA E ATLETAS
}

\section{ELABORATION OF A BAR OF CEREALS AS COMPENSATING FOOD FOR PRACTITIONERS OF PHYSICAL ACTIVITY AND ATHLETE}

\author{
Larissa Grden $^{1}$; Cristina Soltovski de Oliveira²; Eliana A. F. Queiroz Bortolozo ${ }^{3}$ \\ ${ }^{1,2,3}$ Universidade Tecnológica Federal do Paraná - UTFPR - Ponta Grossa - Brasil \\ larigrden@hotmail.com
}

\begin{abstract}
Resumo
Este estudo teve como objetivo a elaboração de uma barra de cereais, com características nutricionais adequadas às necessidades do praticante de atividade física e atleta. Foram utilizados como ingredientes: proteína isolada do soro de leite (Whey Protein), flocos de arroz, aveia em flocos, maltodextrina, suco concentrado de maracujá, glicose, glicerina, inulina, óleo de canola, maçã desidratada, castanha do Pará, sulfato ferroso e ácido ascórbico. Para caracterização do produto, foram realizadas análises físico-químicas de proteína, lipídeos e cinzas. Os valores de fibras, ferro, sódio e vitamina $C$, foram calculados a partir de dados teóricos. Foram realizadas análises microbiológicas e sensoriais. A barra de cereais elaborada apresentou os seguintes valores para cada 50g: 231 kcal de energia; $6 \mathrm{~g}$ de proteína; $31 \mathrm{~g}$ de carboidratos; $10 \mathrm{~g}$ de lipídios; 3,5g de fibras; $2,5 \mathrm{mg}$ de ferro; $7 \mathrm{mg}$ de vitamina $C ; 14,5 . \mathrm{mg}$ de sódio. As análises microbiológicas demonstraram que o produto estava apto para o consumo, que foi testado e aprovado sensorialmente. A barra de cereal elaborada apresentou todos os requisitos para caracterizá-la como um alimento compensador para praticante de atividade física, destacando-se: carboidratos: abaixo de 90\%; proteínas com 65\%, no mínimo, de alto valor biológico; gorduras ricas em ácidos graxos mono e polinsaturados; e opcionalmente vitaminas elou minerais. Assim sendo, poderia ser consumida antes ou após a prática esportiva, a fim de suprir parcialmente o gasto imediato de calorias, gorduras e proteínas.
\end{abstract}

Palavras-chave: barra de cereais, atleta, proteína do soro de leite.

\section{Introdução}

A mudança do estilo de vida e dos hábitos alimentares dos indivíduos afeta a ingestão e as necessidades de nutrientes; por isso, é importante que haja uma alimentação saudável e equilibrada, tanto para atender as necessidades básicas do organismo, quanto para se obter melhor performance na prática esportiva (ROCHA, 1998; VIEBIG e NACIF, 2006). 
Com o crescimento vertiginoso da população que pratica exercícios, surgiu a consciência sobre a importância da nutrição adequada como aliada na manutenção da saúde e melhora do desempenho. A escolha do alimento a ser consumido, assim como a quantidade adequada tem sido motivo de preocupação dos praticantes de atividade física e atletas de competição (PEREIRA et al., 2003).

Para os atletas a alimentação é ainda mais importante, pois a nutrição inadequada às necessidades específicas de cada indivíduo pode prejudicar a saúde e o desempenho durante o processo de treinamento físico (LOLLO et al, 2004). Também em termos de rendimento desportivo, a nutrição é crescentemente considerada como determinante fundamental da condição física geral dos atletas (FRAGOSO, 2006).

Não existe nenhum alimento ou combinação de alimentos que possa compensar a falta de habilidades motoras ou de treinamento, porém a boa nutrição auxilia no preparo físico do individuo, quer seja um atleta, quer seja aquele que estimula seu organismo para melhorar seu condicionamento físico. Portanto, para os indivíduos que desejam um bom condicionamento físico, visando melhorar a saúde, além dos exercícios regulares, o hábito alimentar deve ser atentamente observado (OLIVEIRA e MARCHINI, 1998).

Existe consenso de que a capacidade de rendimento físico tem relação direta com a ingestão equilibrada de todos os nutrientes: carboidratos, gorduras, proteínas, minerais, vitaminas, fibras e água (MOORE, 2002; VIVIANE e GARCIA JUNIOR, 2003). De acordo com Guiselini e Barbanti (1993), a capacidade de um músculo realizar exercícios durante um tempo prolongado depende, entre outras coisas, do suprimento suficiente de sangue, oxigênio e nutrientes.

Para que o atleta tenha seu desempenho máximo é necessário que sua dieta atenda à demanda energética, ofereça um consumo de no mínimo $6 \mathrm{~g}$ de carboidrato por quilo de peso e 1,2g de proteína por quilo de peso e não ultrapasse o limite máximo de ingestão de lipídeos de 30\% do valor energético total (GUERRA, 2002).

A legislação brasileira que fixa a identidade e qualidade de alimentos para praticantes de atividade física determina que os alimentos compensadores devam conter concentração variada de macronutrientes, obedecendo aos seguintes requisitos, no produto pronto para o consumo (BRASIL, 1998): carboidratos: abaixo de 90\%; proteínas: do teor de proteínas presente no produto, no mínimo 65\% deve corresponder à proteína de alto valor biológico; orduras: do teor de gorduras, a relação de 1/3 gordura saturada, 1/3 monoinsaturada e 1/3 poliinsaturada; opcionalmente, podem conter vitaminas e ou minerais.

Vários produtos têm sido desenvolvidos com o objetivo de aprimorar o consumo de nutrientes para aqueles que praticam atividade física e compensar suas necessidades nutricionais específicas. As barras de cereais podem ser uma boa opção para aqueles que praticam atividade física. Podem 
ser consumidos antes ou após a prática esportiva, a fim de suprir o gasto imediato de calorias e proteínas (CLARK, 2002).

Este estudo teve como objetivo elaborar uma barra de cereais com características nutricionais que atendesse às necessidades de praticantes de atividade física e atletas.

\section{Material e Métodos}

Foi elaborada uma barra de cereais, definida como um produto obtido da compactação de cereais, como flocos de aveia e de arroz, podendo ser adicionados de mel, xarope de glicose, açúcar invertido, sal e outras substâncias comestíveis, secos, laminados e tostados (GUIDOLIN e MODENA, 2006).

Os ingredientes foram escolhidos de acordo as necessidades nutricionais de praticantes de atividade física, considerando-se também a pretensão nutricional da barra formulada resultar em um produto compensador. Foram primeiramente pesados em balança de precisão. Os ingredientes líquidos foram aquecidos, seguindo-se a adição dos secos misturados. Foi feita a cocção por dois minutos, sendo então enformada a massa. Após resfriamento natural, realizou-se o corte $(3 \mathrm{~cm} \mathrm{x}$ 2cm) e a secagem em estufa de circulação de ar, sob temperatura de 30 graus, durante 6 horas.

A determinação de lipídios foi realizada pelo método Soxhlet; proteínas pelo método de Kdjhal; cinzas foram determinadas, após carbonização e posterior calcinação em mufla a $550^{\circ} \mathrm{C}$, até peso constante (INTITUTO ADOLFO LUTZ, 1985; CECCHI, 2003);

Para a determinação dos componentes: carboidratos, fibras, ferro, vitamina C, sódio, e energia, utilizaram-se dados teóricos apresentados em tabelas de composição dos alimentos, informações contidas em rótulos dos ingredientes, além das quantidades conhecidas de ferro e vitamina C que foram adicionadas ao produto. No caso dos carboidratos, o cálculo tomou por base a diferença entre o peso da amostra e o total de proteína, lipídios e cinzas.

O valor energético total da barra foi calculado levando-se em conta os valores de carboidratos, proteínas, lipídeos e seus respectivos valores calóricos.

As análises microbiológicas foram realizadas de acordo com a RDC 12, de 02 de janeiro de 2001 (BRASIL, 2001), que estabelece os Padrões Microbiológicos Sanitários para Alimentos e determina os critérios para a conclusão e interpretação dos resultados das análises microbiológicas de alimentos destinados ao consumo humano. Levando-se em consideração o padrão microbiológico para barras de cereais, foram feitas análises para Bacillus cereus, Coliformes a $45^{\circ} \mathrm{C}$ e Salmonella sp.

Para a análise sensorial, foi empregado o método de aceitabilidade, utilizando a escala hedônica (ANZALDUÁ, 1994; CHAVES e SPROESSER, 1996). A amostragem abrangeu uma 
população de quarenta e cinco (45) provadores não treinados, praticantes de atividade física, sendo estes: praticantes de atletismo; de boxe, TaeKwonDo e freqüentadores assíduos de academia. O método utilizado foi a escala hedônica de 9 pontos, variando de 1= desgostei muitíssimo, a 9= gostei muitíssimo.

\section{Resultados e Discussão}

O produto resultante apresentou-se com mais de $80 \%$ de proteína de alto valor biológico (proteína do soro de leite), com possíveis propriedades ergogênicas; frutooligossacarídios e maltodextrina, que fornecem energia durante a atividade física de longa duração; glicose de milho, para fornecimento rápido de energia; flocos de arroz e aveia, para suprimento de energia através de carboidratos complexos e óleo de canola, fonte de ácidos graxos mono e polinsaturados (SICHIERI et al, 2000; SGARBIERI E PACHECO, 1999; PENTEADO, 2003; HIRSCHBRUCH e CARVALHO, 2002; SCHWENK e COSTLEY, 2002;PASSOS e PARK, 2003; LANCHA JUNIOR, 2004).

A suplementação com ferro tomou por base a necessidade maior deste nutriente entre os praticantes de atividade física, reduzindo risco de desenvolvimento de anemia ferropriva. A vitamina $\mathrm{C}$, além de sua ação como antioxidante, é fator reconhecidamente positivo na biodisponibilidade de ferro (MAUGHAN e BURKE, 2004; LANCHA JUNIOR, 2004; SICHIERI et al, 2000).

A Tabela 1 apresenta a composição nutricional, baseada nos resultados das análises físicoquímicas realizadas com a amostra de barra de cereal e nos cálculos teóricos.

Tabela 1 - Composição nutricional da barra de cereais

\begin{tabular}{ccc}
\hline Nutriente & Quantidade em $100 \mathrm{~g}$ & Quantidade em $50 \mathrm{~g}$ \\
\hline Energia & $464 \mathrm{Kcal}$ & $231 \mathrm{kcal}$ \\
Proteína & $12 \mathrm{~g}$ & $6 \mathrm{~g}$ \\
Carboidrato & $62 \mathrm{~g}$ & $31 \mathrm{~g}$ \\
Lipídios & $20 \mathrm{~g}$ & $10 \mathrm{~g}$ \\
Fibras & $7 \mathrm{~g}$ & $3,5 \mathrm{~g}$ \\
Ferro & $5 \mathrm{mg}$ & $2,5 \mathrm{~g}$ \\
Vita mina C & $14 \mathrm{mg}$ & $7 \mathrm{mg}$ \\
Sódio & $29 \mathrm{mg}$ & $14,5 \mathrm{mg}$ \\
\hline
\end{tabular}

O valor energético total da barra em cada 50g totalizou $231 \mathrm{kcal}$, sendo representado por 54\% de carboidratos, $10 \%$ de proteínas e 36\% de lipídios. Este valor energético, assim como a proporção entre os nutrientes calóricos, possibilitaria um bom aproveitamento de cada nutriente. Conforme descrito na literatura, para que o atleta tenha seu desempenho máximo, é necessário que 
sua dieta atenda à demanda energética e ofereça uma proporção entre os nutrientes (GUERRA, 2002).

A determinação de proteínas demonstrou que a barra de cereal possui $12 \mathrm{~g} \%$. Para um individuo de atividade moderada, representaria 16\% das necessidades diárias, podendo ser considerada como fonte de proteínas (TIRAPEGUI, 2005; BACURAU, 2005). O teor de carboidratos foi de 62g\% ou 31g, para cada 50g de barra. Os ingredientes que contribuíram para a totalização destes nutrientes foram selecionados a fim de se obter energia de forma rápida (glicose de milho) e de forma mais lenta (polissacarídeos). A manutenção de uma reserva adequada de energia é substrato ideal para diversos tipos de exercícios físicos (WOLINSKY e HICKSON, 1996; BACURAU, 2005; SAPATA et al., 2006). No tocante a lipídios, o valor de $10 \mathrm{~g}$ para cada 50g de barra foi considerado importante para repor energia gasta durante treinamento ou atividade física, principalmente pelo fato da fonte de lipídios da barra constituir-se de ácidos graxos polinsaturados (óleo de canola). No caso do atleta ou praticante de atividade física, é importante uma reserva de energia na forma de ácidos graxos, em função da depleção das reservas corporais (GUEDES e GUEDES, 2003).

No caso das fibras, o valor de 3,5g para cada 50g de barra, que representa $14 \%$ da ingestão diária recomendada, pode auxiliar na degradação do amido contido nos ingredientes amiláceos, e facilitar o processo fisiológico da digestão (BENDER, 1995; PASSOS e PARK, 2003). Quanto aos altos valores de minerais, representados pelo total de cinzas de 2,12g\%, foram considerados bastante importantes, levando-se em conta que comumente os atletas têm depleção de vários minerais durante a prática esportiva. No caso específico de ferro, o valor de 2,5mg/barra representa 18\% da ingestão diária recomendada, podendo a barra ser, portanto, considerada um alimento rico deste elemento (MAUGHAN e BURKE, 2004; MAHAN e SCOTT-STUMP, 1998).

Para o nutriente mineral sódio, os valores apresentados foram considerados mínimos (ingestão diária recomendada de 2400mg), uma vez que o alimento elaborado não tem como objetivo repor sódio perdido, função específica das bebidas hidroeletrolíticas (BRASIL, 1998). Outrossim, a dieta do atleta não deve ser hipossódica, pois pode colocar em risco o equilíbrio de sódio que poderia contribuir para cãibras (CLARK, 2002).

A barra de cereal elaborada apresentou todos os requisitos para caracterizá-la como um alimento compensador para praticante de atividade física, destacando-se: carboidratos: abaixo de 90\%; proteínas com 65\%, no mínimo, de alto valor biológico; gorduras ricas em ácidos graxos mono e polinsaturados; e opcionalmente vitaminas e/ou minerais (BRASIL, 1998). Assim sendo, poderia ser consumida antes ou após a prática esportiva, a fim de suprir parcialmente o gasto imediato de calorias, gorduras e proteínas. 
As análises microbiológicas demonstraram ausência de coliformes a $45^{\circ}$, Salmonella sp $e$ Bacillus cereus. A partir das análises realizadas, o produto mostrou-se apropriado para consumo humano, de acordo com os padrões legais vigentes (BRASIL, 2001).

$\mathrm{Na}$ análise sensorial, quatro provadores declararam, “desgostei ligeiramente”; oito, “indiferente”; oito, "gostei ligeiramente”; quinze, "gostei bastante”; nove, "gostei muito” e três, “gostei muitíssimo”. A média final do estudo ficou em 7,0. Segundo Monteiro (1982), considera-se o valor 70\%, o mínimo a ser atingido para que se considere aceito o produto. Assim sendo, o produto obteve um índice de aceitação satisfatório.

\title{
4. Conclusão
}

A partir dos resultados apresentados e discutidos, foi possível concluir que a barra elaborada com cereais possui composição nutricional que a caracteriza como barra de cereais para atleta, especificamente como alimento compensador, sugerindo-se estudos futuros, quanto à sua embalagem e vida de prateleira.

\begin{abstract}
This study had as objective the elaboration of a bar of cereals, with characteristics appropriate nutricionais to the apprentice's of physical activity needs and athlete. They were used as ingredients: isolated protein of the serum of milk (Whey Protein), flakes of rice, oat in flakes, maltodextrina, concentrated juice of passion fruit, glucose, glycerin, inulina, canola oil, dehydrated apple, chestnut of Pará, ferrous and acid sulfato ascorbic. For characterization of the product, physical-chemical analyses of protein, lipídeos and ashes were accomplished. The values of fibers, iron, sodium and vitamin C, were calculated starting from theoretical data. Analyses microbiológicas were accomplished and sensorial. The bar of cereals elaborated it presented the following values for each 50g: $231 \mathrm{kcal}$ of energy; $6 \mathrm{~g}$ of protein; $31 \mathrm{~g}$ of carboidratos; $10 \mathrm{~g}$ of lipids; 3,5g of fibers; $2,5 \mathrm{mg}$ of iron; 7mg of vitamin C; 14,5.mg of sodium. The analyses microbiológicas demonstrated that the product was capable for the consumption, that was tested and approved sensorialmente. The cereal bar elaborated it presented all the requirements to characterize her as a food compensador for apprentice of physical activity, standing out: carboidratos: below $90 \%$; proteins with $65 \%$, at least, of high biological value; rich fats in acids graxos monkey and polinsaturados; and opcionalmente vitamins mineral e/ou. Like this being, it could be consumed before or after the sporting practice, in order to supply the immediate expense of calories, fats and proteins partially.
\end{abstract}

Key-words: bar of cereals, athlete, protein of the serum of milk.

\section{Referências}

ANZALDÚA, M. A. La evolución sensorial de los alimentos en la teoria y la practica. Zaragoza, Acribia, 198p., 1994. 
BACURAU, R. F. Nutrição e suplementação esportiva, Phorte, São Paulo, 2005.

BENDER, D. A. Nutrición y el metabolismo. Zaragoza, Acribia,1995.

BRASIL. Portaria $\mathbf{n}^{\circ}$. 222, de 24 de março de 1998. Regulamento Técnico para Fixação de Identidade e Qualidade de Alimentos para Praticantes de Atividade Física. ANVISA.

BRASIL. Resolução RDC $\mathbf{n}^{\mathbf{0}}$. 12, de 2 de janeiro de 2001. Aprova o Regulamento Técnico sobre padrões microbiológicos para alimentos. ANVISA.

CECCHI, H. M. Fundamentos teóricos e práticos em análise de alimentos. Ed. UNICAMP, 2ªed., Campinas, 2003.

CHAVES, J. B. P.; SPROESSER, R. L. Práticas de laboratório de análise sensorial de alimentos e bebidas, UFV, Viçosa, 1996.

CLARK, N. Guia de Nutrição desportiva, São Paulo, Artmed, 2002.

FRAGOSO, I. Nutrição e Actividade Física. Ciências da Motricidade, 2006.

GUEDES, D. P.; GUEDES, J. P. Controle do peso corporal. Composição corporal. Atividade física e nutrição, Rio de Janeiro, SHAPE, 2003.

GUERRA, I. Importância da alimentação do atleta visando a melhora da performance. Nutrição em Pauta, n.55, v.4, p.63-66, 2002.

GUIDOLIN, F.;MODENA A. G. Sistema Brasileiro de Respostas Técnicas, 2006 Disponível em http://sbrt.ibict.br , acesso em 27 set. 2007.

GUISELINI, M. A.; BARBANTI, V. J. Fitness: Manual do instrutor, São Paulo, Balieiro, 1993.

HIRSCHBRUCH, M. D.; CARVALHO, de J. R. Nutrição esportiva: uma visão prática, 1 ed., Manole, 365p., 2002.

INSTITUTO ADOLFO LUTZ. Normas analíticas do Instituto Adolfo Lutz. 3 ed. São Paulo: O Instituto, 1985.

LANCHA JUNIOR, A. H. Nutrição e metabolismo aplicados à atividade motora, São Paulo, Atheneu, 2004.

LOLLO, P. C. B; CAZETTO, F. F.; MONTAGNER, P. C. Aspectos nutricionais da competição de judô em crianças e adolescentes, Revista digital, Buenos Aires, 2004.

MAHAN, L. K.; SCOTT-STUMP, S. Alimentos, nutriçao e dietoterapia. Roca, Sçao Paulo, 1998.

MAUGHAN, R. J.; BURKE, L. M. Nutrição Esportiva: Manual de Ciência e Nutrição Esportiva, Porto Alegre, Artmed, 2004.

MONTEIRO, C. Técnicas de avaliação sensorial, $2^{\circ}$ edição, UFPR, Curitiba, 1982.

MOORE, M. C. Nutrição e dietoterapia: Manual prático, Rio de Janeiro, Revinter, 2002.

OLIVEIRA, J. E D. de.; MARCHINI, J. S. Ciências Nutricionais, São Paulo, Sarvier, 1998.

PASSOS, L. M. L.; PARK, Y. K. Frutooligossacarídeos: implicações na saúde humana e utilização em alimentos. Ciência Rural, v.33, n.2, Santa Maria, 2003.

PENTEADO, M. de V. C. Vitaminas: aspectos nutricionais, bioquímicos, clínicos e analíticos. Manole, 2003.

PEREIRA, R.F.; LAJOLO, F. M.; HIRSCHBRUCH, M. D. Consumo de suplementos por alunos de academias de ginástica em São Paulo, Revista de Nutrição, n. 16, v.3, p. 265-72, 2003.

ROCHA,L.P; PEREIRA, M.V.L.Consumo de suplementos nutricionais por praticantes de exercícios físicos em academias. Revista de Nutrição, n.11, v. 2, p.76-82, 1998.

SAPATA, K. B.; FAYH, A. P. T.; OLIVEIRA, A. R. de. Efeitos do consumo prévio de carboidratos sobre a resposta glicêmica e desempenho. Revista Brasileira de Medicina e Esporte, v.12, n4, Rio Grande do Sul, 2006. 
SCHWENK, T.L.; COSTLEY, C.D. When food ecomes a drug: nonanabolic nutritional supplement use in athletes. Am. J. Sports Med, v.30, n.17, p.907-916, 2002.

SGARBIERI, V.C; PACHECO, MTB. Alimentos funcionais fisiológicos. Braz. J. Food Technol., n.2, p. 2-7, 1999.

SICHIERI, R.; COITINHO, D. C.; MONTEIRO, J. B. Recomendações de Alimentação e Nutrição Saudável para a População Brasileira. Arquivos Brasileiros de Endocrinologia\& Metabologia, São Paulo, 2000.

TIRAPEGUI, J. Nutrição, Metabolismo e Suplementação na Atividade Física.,São Paulo, Atheneu, 2005.

VIEBIG, R. F.; NACIF, M, de A. L. Recomendações nutricionais para a atividade física e o esporte. Revista Brasileira de Educação Física, Esporte, Lazer e Dança, São Paulo, v.1, n. 1, p. 2-14, 2006.

VIVIANE, M. T.; GARCIA JUNIOR, J. R. Análise dos conhecimentos sobre nutrição básica e aplicada de profissionais de Educação física e nutrição. Nutrição em pauta, São Paulo, 2003.

WOLINSKY, I; HICKSON, J F J. Nutrição no exercício e no esporte, 2ª ed., 548p., São Paulo, Roca, 1996.

\section{Dados do primeiro autor:}

Nome completo: Larissa Grden

Filiação institucional: UTFPR

Função ou cargo ocupado: Tecnóloga em Alimentos

Endereço completo para correspondência (bairro, cidade, estado, país e CEP): Caramuru, n¹5, Jardim Maracanã

Telefones para contato: (42) 9944-2014

e-mail:larigrden@hotmail.com 